EFFECT OF MEDIA ON THE FORMATION OF THE ANTIBIOTIC ACTIVITY BY $A$. griseus (WAKSMAN'S STRAIN)
Incubation temperature, $28^{\circ} \mathrm{C}$. (mean)

\begin{tabular}{|c|c|c|}
\hline \multirow{2}{*}{$\begin{array}{c}\text { Number of days } \\
\text { after inoculation }\end{array}$} & \multicolumn{2}{|c|}{ Mean halo-diameter of duplicates in millimetres } \\
\cline { 2 - 3 } & Enzyme digest media & Schatz-Waksman media \\
\hline 1 & Nil & Nil \\
2 & 12 & $"$, \\
3 & 10 & $"$, \\
4 & 13 & $10^{\prime} \cdot 5$ \\
6 & 16 & 13 \\
7 & 17 & 14 \\
8 & 10 & $14 \cdot 5$ \\
9 & Nil & 13 \\
10 &,$"$ & 13 \\
11 & Nil \\
12 &, &, \\
\hline
\end{tabular}

and placed in a slanting position at an angle of $20^{\circ}-30^{\circ}$ so as to offer a large surface for growth. A similar experiment was carried out with $B$. subtilis as the test organism, at the end of every twenty-four hours, B. subtilis as the test organism, at the end of every twenty-four hours,
by drawing out tubes from the incubator. The results are summarized by drawing out tubes from the

The results in the table clearly show that the groundnut-cake hydrolysate contains the factors necessary for the production of antihydrolysate contains the factors necessary for the production of anticake hydrolysate, the presence of the antibiotic is detectable within cake hydrolysate, the presence of the antibiotic is detectable within forty-eight hours of inoculation. The maximum antibiotic activity is reached between the lyf th and sixth day. After the sixth day the activity decreases rapidly until the eighth day, when no activity can be detected. In the case of Schatz-Waksman media the picture is entirely different. It is only between the fourth and the fifth day that the presence of the antibiotic is indicated. Maximum activity is reached between the eighth and the ninth day. However, in this case the destruction of the antibiotic after reaching the peak activity is more gradual than in the case of groundnut-cake hydrolysate. Thus it is seen that groundnut-cake hydrolysate can be effectively used in the place of Schatz-Waksman media. We are also investigating the aminoacid and vitamin requirements of $\boldsymbol{A}$. griseus for the production of antibiotic activity. The detailed results of our investigation will be published elsewhere.

Our thanks are due to Prof. V. Subrahmanyan, Drs. N. N. De and K.P.Menon for their interest in our work. We gratefully acknowledge the generous support from the Council of Scientiflc and Industrial Research, Delhi, under the auspices of which this work is being carried out. R. RAGHUNANDANA RAO

Department of Biochemistry,
Indian Institute of Science, P. R. VENKATARAMAN Bangalore.

4 Waksman, S. A., et al., Proc. Soc. Exp. Biol. and Med., 55, 66 (1944). 2 Schatz and Waksman, Proc. Soc. Exp. Biol. and Med., $5 \%, 244$ (1944). a Robinson et al., Proc. Soc. Exp. Biol. and Med., 57, 216 (1944).

4 Waksman et al., Proc. Staff Meetings, Mayo Clinic, 19, 537 (1944). Heilman, Proc. Staff Meetings, Mayo Clinic, 19, 533 (1944)

Feldman and Hinshaw, Proc. Staff Meetings, Mayo Clinic, 19, 593 (1944).

7 Heilman, Proc. Staff Meetings, Mayo Clinic, 20, 33 (1945).

isones et al., Science, 100, 103 (1944).

- Reimann et al., J. Amer. Med. Assoc., 121, 175 (1945).

${ }^{10}$ Le Page and Campbell, J. Biol. Chem., 162, 183 (1946).

"Wodruff and Foster, J. Bact., 47, 43 (1944).

\section{Presence of Fibrinogen in the Yolk Sac Content of Rabbits}

INVESTIGATIONS of the prenatal mortality in wild rabbits ${ }^{1,2,3}$ led us to examine embryologically many 8-,9- and 10-day embryos. It was found that in a substantial proportion of these the yolk sac content could be seen macroscopically to be gelatinous and to contain an irregular network of fine flbrils. Microscopic examination revealed the presence of a fine reticulum in the yolk sac. This reticulum resembled histologically sections of a fibrin clot prepared from blood plasma that had been flxed and stained by the same technique. For
this and other reasons it was suspected that the reticulum in the yolk sac was, in fact, fibrin.

An attempt was made therefore to determine experimentally if fibrinogen was normally present in the yolk sac content of 9-day embryos of tame rabbits. The fluid was aspirated by means of a hypodermic syringe from the uterine swellings while the animal was under ether anæesthesia. and was citrated. By this means it was possible to obtain approximately $0.5 \mathrm{ml}$. from each 9 -day embryo. Care was taken to avoid contamination of the fluid with blood, and any samples in which this occurred were rejected. It was impracticable to ensure that the fluid content of the yolk sac so withdrawn was not contaminated with traces of embryonic fluid from the exocœl or with tissue exudate from the uterine lumen, but it is certain that the amount of such contamination, if any, was small. A solution of human thrombin was then added to the aspirated fluid and resulted in the rapid formation of a clot in all cases.

It must be concluded therefore that flbrinogen is normally present in substantial amounts in the yolk sac content of rabbit embryos. The concentration is too great to be accounted for by the possible contamination of the yolk sac fluid with traces of other embryonic or maternal fluids. Since the vascular system of the embryo is in an early stage of development at this time, it is probable that the fibrinogen in the yolk sac is of maternal origin. It was possible to estimate that the concentration of fibrinogen in the aspirated fluid was of the orde of $50 \mathrm{per}$ cent of that in blood plasma by comparison of the clots
formed in parallel series of dilutions of the yolk sac thuid and of blood formed in parallel series of dilutic

It is hoped to publish a full account of this work elsewhere, and further investigations are in progress. We would like to take this further investigations are in progress. We would like to take this vising us on the hæmatological technique and to the Medical Research Council's Serum Unit at the Lister Institute for kindly providing us with the human thrombin employed. We are indebted to the Agripart.

$$
\begin{gathered}
\text { Department of Zoology, } \\
\text { University College of North Wales, } \\
\text { Bangor. } \\
\text { May } 25 .
\end{gathered}
$$

1 Brambell, F. W. R., Proc. Roy. Soc., B, 130, 462 (1942). 2 Brambell, F. W. R., Proc. Zool. Soc. Lond., 114, 1 (1944). ${ }^{2}$ Brambell, F. W. R., Proc. Zool. Soc. Lond., 114, 1 (1944).

\section{F. W. Rogers Brambeli} IVOR H. MILIS

\section{(a)}

An Antibiotically Active and Slightly Pathogenic Member of the Bac. brevis Group Found in Man

A TWENTY-YEAR old male Arab was admitted to the Government Hospital, Haifa, and died two hours after admission. Post-mortem examination performed about one hour after death revealed as cause of death complete occlusion of the jejunum by multiple intussusceptions, obviously brought about by masses of Ascarids present in the small intestines. But in addition to this condition, all lymphatic glands in the mesentery were found to be considerably enlarged and hard. The liver was slightly enlarged, the spleen showing no abnormality. Histologically, the mesenteric glands showed a marked disruption of their architecture; there was partial destruction of the lymphatic tissue with replacement by reticulo-endothelial hyperplasia, suggesting an inflammatory process of some duration. There were no signs of tuberculosis. Small necrotic foci were found in the liver.

In smears from the enlarged glands, no acid-fast organisms were found, but numerous capsulated Gram-negative bacilli were present. By culturing the glandular fluid on blood agar plates, rich pure cultures of these bacilli were obtained which, on further examination, proved to belong to the Bac. brevis group. They were non-pathogenic for rabbits and guinea pigs.

In the agar-plate test the strain inhibited the growth of Staphylococcus aureus, $\alpha$ - and $\beta$-hæmolytic streptococci, pneumococci and $P$. pestis.
There was no inhibitory effect upon members of the typhoid-coli group and on the inbibiting strain itself.

Antibiotically active cell-free watery extracts could be prepared Antibiotically active cell-free watery extracts could be prepared
from cultures on Dorset's egg medium (which is liquefled by the from cultures on Dorset's egg medium (which is liquefled by the
bacillus) and from surface cultures on peptone-water. These extracts caused lysis, at $p \mathbf{H} 7 \cdot 0-7 \cdot 2$, of all the organisms inhibited in the plate experiment and also of its own parent strain and of cultures of Paramecium caudatum.

The active principle is soluble in water, ethyl and $n$-butyl alcohol, but insoluble in ether, petrol ether and carbon tetrachloride.

The peculiar features of this strain are its origin, its pathogenic effect on the human lymphatic tissue, and the apparent difference of its active principle from tyrothricin.

Government Laboratory, RUDOLPH REITLER Haifa.
May 27.

\section{Resolution and Synthesis of Virus Complexes Causing Strawberry Yellow-edge}

Preliminary experiments on the resolution of strawberry virus complexes have shown that, after feeding for twenty-four hours on a plant infected with 'yellow-edge', the vector Capitophorus fragarioe Theob. transmits a single virus which is believed to be the 'mild crinkle' virus. This virus is transmitted after infection-fee ding periods of 1 hour or more, persists for only a few hours in the vector and pro-
duces faint chlorotic spots on the leaves of Royal Sovereign strawberry ${ }^{1}$.

Work by Wood and Whitehead at Bangor ${ }^{2}$ has shown that two distinct viruses (one of which is more persistent than the other) can be isolated from plants infected with 'severe crinkle'. I have shown in more recent work that a persistent virus can also be isolated from plants infected with yellow-edge and that this virus is apparently distinet from the persistent virus of Wood and Whitehead. It has now been found that the combined action of the two viruses isolated from a plant infected with yellow-edge produces yellow-edge.

Aphids ( $C$. fragarice) fed for ten days on a Royal Sovereign plant infected with yellow-edge are transferred to uninfected plants of Fragaria vesca, and after feeding there for twenty-four hours are retransferred to a second series of uninfected $F$. vesca plants. The plants of the second series do not hecome infected with the 'mild crinkle virus (since this virus does not persist in the vector), but number of them develop symptoms of a mild type, namely,

spotting often accompanied by slight cupping of the leaves.
The virus producing these symptoms is retransmitted after infectionThe virus producing these symptoms is retransmitted after infection-
feeding periods of twenty-four hours or more, persists in the vector feeding periods of twenty-four hours or more, persists in the vector
for several days and produces very mild and scarcely distinguishable for several days and produces very mild and scarcely distinguishable is thus distinct from the mild crinkle virus already isolated, and will 